\title{
Narrativas de identidad. De la nación mestiza a los recientes desplazamientos de la metáfora social en Bolivia
}

\author{
Narratives of Identity. From the Mestizo Nation to \\ Recent Shifts of the Social Metaphor in Bolivia \\ Narrativas de identidade. Da nação mestiça para os recentes \\ deslocamentos da metáfora social na Bolívia
}

\section{Javier Sanjinés}

UNIVERSITY OF MICHIGAN, ANN ARBOR

Profesor del Departamento de Lenguas y Literaturas Romances de la

Universidad de Michigan, Ann Arbor. PhD en Filosofía, University

of Minnesota. Ha escrito, entre otros, Mestizaje Upside Down.

Aesthetic Politics in Modern Bolivia (University of Pittsburgh Press, 2004) y Embers of the Past. Essays in Times of Decolonization (Duke

University Press, 2014). Correo electrónico: sanjines@umich.edu

\section{Artículo de reflexión}

Una primera versión de este artículo fue publicada originalmente en el número 31 de T’inkazos. Revista Boliviana de Ciencias Sociales, editada por el Programa de Investigación Estratégica en Bolivia (PIEB), en junio de 2012.

Documento accesible en línea desde la siguiente dirección: http://revistas.javeriana.edu.co 


\section{Resumen}

Este ensayo afirma que la construcción de la nación estuvo ligada a narrativas (novelas y ensayos) de identidad. Las primeras narrativas identitarias, que elaboraron importantes metáforas, como la del mestizaje ideal, controlaron celosamente el ascenso social del indígena. Después de regimentar al indio bajo la férrea noción tamayana de la pedagogía nacional, Sanjinés procede a desterritorializar la identidad idealizada de lo mestizo desde tres nuevas versiones que le dan fluidez a la metáfora social: la metáfora del río, la de la avalancha de la plebe y la del anfibio cultural.

Palabras clave: identidad, mestizaje, nación, Bolivia.

Palabras descriptor: Identidad cultural, mestizaje en la literatura, mestizaje indígena, pedagogía social

\section{Abstract}

This paper argues that the construction of the "nation" was linked to narratives of identity (novels and essays). The first narrative identities that produced important metaphors, such as the one about ideal crossbreeding, jealously controlled the social climb of indigenous people. After regimenting the native people under the tough Tamayo's notion of national pedagogy, Sanjinés proceeds to deterritorialize the idealized mestizo identity from three new versions that give fluidity to the social metaphor: the metaphor of the river, the one about an avalanche of the plebs and another about a cultural amphibian.

Keywords: identity, crossbreeding, nation, Bolivia. Keywords plus: Cultural identity, mestizaje indígena, indians, indians-mexi bloods, social teaching

\section{Resumo}

Este ensaio afirma que a construção da "nação" esteve ligada a narrativas (romances e ensaios) de identidade. As primeiras narrativas identitárias que produziram metáforas importantes, como a da miscigenação ideal, controlaram ciosamente a ascensão social do indígena. Após regimentar o índio sob a férrea noção tamaiana da pedagogia nacional, Sanjinés procede a desterritorializar a identidade idealizada do mestiço desde três novas versões que dão fluidez à metáfora social: a metáfora do rio, a da avalancha da plebe e a do anfíbio cultural.

Palavras-chave: identidade, mestiçagem, nação, Bolívia Palavras-chave descritores: Identidade cultural, hibridismo na literatura, mestiçagem indígena, pedagogia social

RECIBIDO: 13 DE MARZO DE 2013. EVALUADO: 22 DE ABRIL DE 2013. ACEPTADO: 25 DE ABRIL DE 2013.

\section{Cómo citar este artículo:}

Sanjinés, Javier. "Narrativas de identidad. De la nación mestiza a los recientes desplazamientos de la metáfora social en Bolivia". Cuadernos de Literatura 18.35 (2014): 28-48. 
Afirma el hist oriador mexicano Tomás Pérez Vejo que la historia de los últimos dos siglos sería ininteligible sin el término nación (276). En efecto, este concepto ha terminado convirtiéndose en la forma hegemónica más importante de la identidad colectiva de la modernidad, y ha sido, además, la fuente de legitimación del poder político. Realidad insoslayable desde el siglo XVIII, la nación, concepto que regula la mayor parte de los aspectos de la vida colectiva, fue, junto a la noción de progreso, la nueva religión de Occidente. Incluso más allá de los otros mitos de la modernidad, incluyendo la razón y el propio progreso, es la única construcción social que permance indemne a las grandes convulsiones históricas del siglo pasado, de manera que, como señala Pérez Vejo, "la bondad de la nación como forma natural y deseable de organización social sigue gozando de un amplio consenso en la mayoría del planeta" (277).

Pero la nación no es un hecho "natural" ni universal. No ha existido siempre e incluso podría dejar de existir en el futuro. Creada por el desarrollo de la modernidad, es simplemente una respuesta histórica concreta a los problemas de identidad y de legitimación del poder. Por este motivo, y a diferencia de otras identidades colectivas, como las religiones, los estamentos y los grupos familiares, ella tiene ese carácter político preciso que hace que se confunda con el Estado, razón por la cual Pérez Vejo considera que el término Estado-nación no es más que "un pleonasmo semántico" (280). Pleonásmico en la medida en que todo Estado necesita de una nación y toda nación aspira a ser un Estado, el Estado-nación responde a la modernidad de la nación, pero no a la "existencia de comunidades humanas que a lo largo de la historia han sido identificadas como naciones" (281). Así, el término nación existió antes de la modernidad europea, "pero con significado muy diferente del que comenzó a tener hacia finales del siglo XVIII, tanto en lo que se refiere a su sentido, como, sobre todo, a su uso político" (281).

$\mathrm{Si}$, como construcción social, las naciones no son realidades objetivas, sino invenciones colectivas, ellas no son el resultado de una larga evolución histórica, sino el de una relativamente corta invención "voluntarista" (la nación cívica), opuesta a la "organicista" (la nación étnica). En efecto, como observara el estudio promovido por la Unidad de Coordinación de la Asamblea Constituyente (Mayorga y Molina) a propósito de la realidad boliviana, la nación cívica y la nación étnica son entidades que, al oponerse entre sí, pesaron sustancialmente en el desarrollo del nacionalismo. Anthony Smith (The Ethnic Origins; The Ethnic Revival) y Benedict Anderson coinciden en afirmar que los dos tipos no siguen el mismo derrotero. "Primordialista", Smith se apega mucho más al pasado, al hecho de que las tradiciones étnicas continúan actuando en el presente, mientras que Anderson, moderno en su concepción de la nación, y siguiendo la lógica de 
la comunidad imaginada, se desentiende de las tradiciones pasadas que nada tienen que ver con la función de los medios de comunicación y con el rol modernizador del Estado (Calhoun 28).

Volviendo al caso boliviano, habría que enfatizar el hecho de que tanto la nación cívica como la nación étnica fueron concepciones elitistas que dieron como resultado la forma cultural que llamaré pedagógica, la misma que incluyó a los más importantes ensayistas del siglo XX.

\section{Metáforas en torno a la "pedagogía nacional"}

El crítico chileno Hernán Vidal, quien más investigó sobre las narrativas de identidad, las conceptuó como verdaderas artífices de la cultura nacional. Como en muchos de sus otros trabajos", Vidal expresa en su ensayo "An Aesthetic Approach to Issues of Human Rights" que todo el campo de las humanidades está regido por el "estudio de cómo los seres humanos crean sistemas simbólicos, analógicos, que dotan de sentido a su actuar en el entorno social". Para Vidal, los seres humanos ejercitan sus actos estéticos "como campos coherentes de respuestas corporales emotivo-intelectuales" (14) a los problemas que encuentran en la sociedad. Es claro que para Vidal, a quien sigo en la conceptualización de la identidad, los ensayos son parte de estas narrativas que fundan la nación.

Difundido por textos literarios -las crónicas y, posteriormente, los ensayos y las novelas- que representaban imaginariamente la situación contemporánea de la cultura patria, el proceso histórico de construcción de la nación tuvo una larga e importante trayectoria que, en el caso de América Latina, estuvo relacionada con conocidos ensayos que guiaron la formación de las diversas "culturas nacionales".

Ligados al capitalismo de imprenta estudiado por Benedict Anderson², los ensayos "fundacionales" que incorporo brevemente en este apartado ${ }^{3}$ se

$1 \quad$ El autor recopila sus ensayos en La literatura en la historia de las emancipaciones latinoamericanas.

2 Por capitalismo de imprenta Anderson entiende tres cosas: 1) que el lenguaje culto (el latín y las lenguas que derivaron de él) fue primordial para la construcción de la nación. El nacionalismo privilegió el uso de las lenguas vernáculas por sobre el latín. De este modo, la coincidencia entre el capitalismo y la tecnología de imprenta dio a la lengua su estrecha relación con el nacionalismo; 2) la capacidad de que determinadas lenguas -aquellas que adquirieron fijeza y estabilidad en el empleo de la gramática-dominasen el aparato administrativo del Estado; 3) la construcción de una "alta cultura", capaz de dominar a la sociedad y de definirla de acuerdo con su capacidad "totalizadora".

3 Ver el análisis más detallado de los ensayos de Alcides Arguedas, Franz Tamayo y Carlos Montenegro, en mi libro El espejismo del mestizaje. 
escribieron durante la primera mitad del siglo pasado. Estos ensayos eran construcciones imaginarias, es decir, interpretaciones históricas sui géneris que creaban campos metafórico-simbólicos capaces de orientar el orden social establecido. Involucrados en la construcción de la nación, los "letrados" tuvieron la capacidad de representar lo público sin ser propiamente historiadores, sociólogos o cientistas sociales. Se trataba, más bien, de "hombres de letras" que estaban "en relación simbólica con el tiempo en que les tocó vivir", como bien dijo Edward Said acerca de este tipo de escritores.

Hago hincapié en el hecho de que olvidamos con frecuencia el carácter "representacional" de estos ensayos fundacionales, es decir, que eran representaciones imaginarias de la realidad -entre lo real y lo representado, más que los hechos en sí mismos, importaba la manera de fundamentarlos, de argumentarlos-, no encuestas sociológicas ni documentos históricos directamente explicativos de la realidad. Mediados por símbolos y por metáforas, los ensayos fundacionales de la nación boliviana eran la representación imaginaria de cómo determinados grupos y clases sociales reproducían su existencia, siguiendo o rompiendo con patrones establecidos por el poder político hegemónico.

Considerado polémico por la élite intelectual de la época, uno de tales ensayos, y el primero en desarrollar la cultura del antimestizaje ${ }^{4}$, fue Pueblo enfermo, ensayo del polémico escritor paceño Alcides Arguedas, al que me refiero muy brevemente en este trabajo. Quiero simplemente resaltar que, incapacitado para moldear el nosotros histórico que es el centro neurálgico de la construcción del Estado-nación, Arguedas observó la realidad boliviana a partir de la metáfora de la enfermedad. Así, la enfermedad como metáfora, expresión que nos recuerda el título de uno de los libros de Susan Sontag, terminó siendo el modelo icónico ${ }^{5}$ desde el cual Arguedas representó la degeneración psicobiológica de la sociedad boliviana, realidad a la cual observó descarnadamente.

A lo largo del ensayo de Arguedas, la incurable enfermedad que acarreaba la raza mestiza explicaba la disfunción del todo social. En efecto, el mestizaje,

4 Acuñada por la historiadora Brooke Larson, esta expresión reúne a los ensayistas liberales de las primeras décadas del siglo XX, quienes, afanados en construir el Estado-nación, y bajo una impronta fuertemente marcada por el darwinismo social de la época, consideraban que "la raza mestiza no unía ni fusionaba a indios y blancos, sino que encarnaba lo peor de ambas razas: la audacia, aventurerismo y fanatismo de los españoles y la pasividad, primitividad y pusilanimidad del indio". En otras palabras, "el mestizaje eliminaba las cualidades redimibles de esas 'razas puras', mientras que, al perpetuar las características envilecidas del conquistador y del conquistado, la híbrida raza mestiza encarnaba una volátil mezcla de gente ingobernable" (33).

5 El lector tiene un estudio detallado de la metáfora social en A Poetic for Sociology, de Richard Harvey Brown (77-171). 
barómetro de la degeneración humana, resultaba ser el mal que atacaba al cuerpo social, que invadía a todos los grupos y a todos los sectores sociales, incluyendo a blancos y a indios "acholados" que pretendían subir en la escala social. Este culto del antimestizaje, que renovaba en Bolivia el pensamiento de Gustave Le Bon y de Octavio Bunge, su discípulo, afirmaba, como lo expresa Brooke Larson, que Arguedas "creía que las razas híbridas estaban caracterizadas por desbalances psicológicos y deficiencias morales, y que la Bolivia contemporánea estaba sufriendo las consecuencias de una raza mezclada" (35), hecho que podía ampliarse al hibridismo del conquistador español-árabe.

Pero el culto del antimestizaje no resultó ser un concepto igualmente apto para explicar el pensamiento de Franz Tamayo, el otro gran "letrado" de ese momento, adversario intelectual de Arguedas ${ }^{6}$. Tamayo se desvió imaginativamente del "antimestizaje", aceptado por el positivismo de la época, y propuso mirar, desde una concepción "organicista" germana, más estrechamente la cultura local, y se alejó así del darwinismo social dominante a principios del siglo XX.

Puesto que Alcides Arguedas había dejado incumplida la tarea de curar la nación, Tamayo planteó la respuesta regeneradora, a través de un cambio metafórico que reubicó lo social y que engrandeció la cultura local. Surgió así la respuesta étnica que contrarrestó el impasse social expuesto por lo cívico. A través de ella, Tamayo pudo observar las fuerzas vitales de la nacionalidad. Creación de la pedagogía nacional propuso, de este modo, una renovadora metáfora icónica el cuerpo esbelto del indio gobernado por la inteligencia del mestizo- que, como se puede apreciar, exaltó al indio como "depositario de la energía nacional", aunque le dio también su lugar a la inteligencia del mestizo. La nueva metáfora fue acomodando los factores "internos" de la cultura a los factores "externos" del progreso occidental que la vitalidad indígena no tomó en cuenta o desdeñó abiertamente. Duro como el medio ambiente en el que habitaba, el indio resistía con una vocación extraña los embates de la civilización occidental. La resistencia a cambiar y a aceptar pasivamente los elementos exógenos de la civilización era una virtud y también un defecto del carácter de esta raza. Así, la nueva metáfora visualizaba, más allá de la enfermedad racial expresada en el ensayo de Arguedas, que el indio era un cuerpo y una voluntad que perdurarían. Su alma, replegada sobre sí misma, explicaba la psicología del aymara. Desprovisto de inteligencia, el indio era pura voluntad y carácter, ajeno a toda imaginación estética y a todo

6 Una revisión crítica de este culto del antimestizaje, que coincide con mis afirmaciones en torno a la figura intelectual de Franz Tamayo, se encuentra en el reciente libro de Ximena Soruco Sologuren, La ciudad de los cholos. Mestizaje y colonialidad en Bolivia, siglos XIX y XX. 
pensamiento metafísico. Resultaba entonces vano buscar en la raza aymara los matices de una inteligencia superior. Esta era una cualidad del mestizo, quien revelaba facilidad comprensiva, vivacidad intelectual y habilidad para captar las formas estéticas. El mestizo, sin embargo, no tenía la voluntad del europeo. Hábil para copiar, pero sin la voluntad suficiente como para crear algo genuinamente propio, el mestizo no sabía imprimirles el sello de su voluntad a las cosas.

En su construcción de la nación étnica, era posible que las claras diferencias que Tamayo encontró entre el indio y el mestizo se superasen aplicando a las razas roles pedagógicos diferentes: la educación del indio demandaba una pedagogía de amorosa paciencia; la instrucción del mestizo, una disciplina que desarrollase su intelecto. Como puede apreciarse, ambas pedagogías tenían finalidades diferentes, pero se complementaban de una manera interesante: la del indio operaba desde la voluntad y desde la regia contextura de su cuerpo; la del mestizo, desde la cabeza, desde la inteligencia. Esta propuesta configuró una imagen ideal -el mestizaje ideal- que relacionó al indio con el mestizo acriollado, con el mestizo occidentalizado, pero que impidió, mediante el riguroso control del imaginario social, que el indio se transformase en cholo y ascendiese política y socialmente ${ }^{7}$. Este será el desplazamiento metafórico que más tarde abordaré como uno de los factores fundamentales de la vertiente desterritorializadora de la nación. Por ahora, basta con decir que mestizo ideal no era el cholo, actor social que Tamayo borró del imaginario nacional. En efecto, hubo que esperar hasta las décadas de 1930 y de 1940 para que la élite de letrados se despojase del aura mística que envolvía a este mestizaje ideal, y para que forjase una nueva propuesta ideológica, más abarcadora y democratizante, que relacionase, "suturase", lo cívico con lo étnico. Así surgieron letrados tan importantes como Augusto Céspedes y Carlos Montenegro, intelectuales de una clase media emergente, e importantes letrados disidentes, forjadores de la corriente "nacionalista revolucionaria".

El atemperado discurso mestizo de Montenegro superó odiosas distinciones y controles raciales, particularmente la separación entre mestizos y cholos. De este modo, el discurso de Montenegro pasó a formar parte del proyecto letrado de la construcción de la nación, aunque con objetivos diferentes a los que planteaban los promotores de la "cultura del mestizaje", que proponían el disciplinamiento del sector indígena subalterno.

7 Estudios recientes prueban que el control ejercitado por el mestizaje ideal corre a lo largo de toda la "narrativa de la identidad", hasta el proyecto nacionalista cristalizado en la Revolución Nacional de 1952. Ver Soruco. 
El ensayo de Montenegro fue un intento radical de cambiar el "culto del mestizaje", tal cual este había sido construido por el relativamente compacto grupo de letrados oligárquico-liberales. Munido de una nueva propuesta ideológica -la metáfora nación vs. antinación-, el grupo de intelectuales disidentes era ahora llamado a reemplazar la esfera cultural del liberalismo. Esta nueva propuesta, que seguía siendo letrada, impuesta por una intelligentsia revolucionaria que pensaba desde los sectores disidentes de clase media, debía ser mucho más accesible a las masas populares y capaz de conectar con lo que Montenegro denominó los "nervios vitales" de la nacionalidad.

El nacionalismo de Montenegro es un concepto relativamente vago, pero eficaz porque le confiere a Nacionalismo y coloniaje una particular orientación ideológica: la nación debía sobreponerse a las oscuras fuerzas del pasado y servir de bastión contra la rapacidad imperialista permitida y sacramentada por el sistema tradicional: la antinación. De manera sugerente, y aunque inadvertido por los estudios exclusivamente políticos o sociológicos de este ensayo, cabe notar que la metáfora del mestizaje ideal no se ha ido del todo. La función de esta metáfora corporal, corregida y desmitificada, se encuentra vinculada a la lucha política de inicios de los cuarenta. Montenegro, quien creía en el poder de la literatura, interpretó esta metáfora cultural por medio de una extensa analogía literaria, y llamó a cada capítulo de su libro con el nombre de un género literario distinto. Ataviado de épica, después de drama, luego de comedia, el mestizaje siguió teniendo su lugar en la visión del nacionalismo que Montenegro nos legó. Al final, de manera consistente con su argumento -el contenido de la nación fue degradado por la antinación oligárquica-liberal-, Montenegro vio en la novela la posibilidad de urdir una forma nueva que, guiándose por las masas, por la "nación verdadera", lograse superar el pasado alienante.

En resumen, las metáforas constitutivas de la nación cívica y de la nación étnica dieron sentido a fronteras territoriales que, cual murallas o diques, impidieron el libre flujo de las identidades y controlaron celosamente la construcción elitista de lo social. En efecto, ambas concepciones de nación dieron lugar a fronteras duras -así las llama el historiador indio Prasenjit Duara, a propósito de su estudio sobre la China moderna- que fueron asumidas por élites que no pudieron construir proyectos auténticamente hegemónicos de "cultura nacional". En su reemplazo, la cultura del antimestizaje, al igual que la del mestizaje ideal, asentada en las metáforas de la enfermedad mestiza y de la regeneración corporal india, construyeron el Estado-nación sujeto a discursos de dominación que "excluían los valores culturales de los pueblos indígenas y de la mayoría de la población respecto de los derechos de la ciudadanía" (Mayorga y Molina 32). Si 
la nación cívica fue un proyecto limitado a la expansión burocrática del criollaje, sin la correspondiente ampliación de los derechos de ciudadanía, la nación étnica también fue elitista porque buscó incorporar al indio bajo un idealismo abstracto que lo mantuvo postergado en lo concreto. Así, la nación étnica pretendió ser modelada bajo el proyecto de una nación mestiza promovida mediante propuestas pedagógicas de índole "civilizatoria".

Hoy en día se percibe, sin embargo, la necesidad de ir más allá, de superar la naturaleza dura, fija, homogénea de este Estado-nación. Así, surgen argumentos nuevos, posicionamientos ideológicos y discursivos de diversa naturaleza (posmodernos, poscoloniales, etc.) que cuestionan la rigidez de las fronteras construidas por el nacionalismo, la moderna narrativa reguladora de la historia. $\mathrm{Al}$ contrarrestar esta fijeza con la naturaleza mucho más fluida y cambiante de las múltiples identidades que viven dentro de la nación -hoy día empleamos los términos nación plural, plurinacionalidad-, la tarea de extraer al Estado-nación de las fronteras duras de la modernidad es una posibilidad que, aunque necesaria, no deja de ser problemática. De todos modos, nuevas demandas de ciudadanización, provenientes de los procesos migratorios internos de las últimas décadas, provocan el resquebrajamiento de esta frontera dura, de condición mestiza, y hacen la metáfora mucho más fluida, mucho más sensible a las reivindicaciones étnicas asumidas por los movimientos sociales. Se construye así la otredad, hecho que pone en evidencia las limitaciones de la nación concebida como comunidad homogénea. Ingreso, pues, a una nueva etapa, a una nueva vertiente interpretativa de lo nacional.

\section{Desterritorialización y metáforas del fluir}

En el caso boliviano, desterritorialización y desplazamiento son conceptos nuevos que estuvieron relacionados con el abigarramiento social que descubrió René Zavaleta Mercado. Fue Zavaleta (Bolivia; "Forma clase") quien se apartó del modelo icónico de la nación mestiza y abrió el cauce a una de las más interesantes lecturas desterritorializadoras del presente: la planteada por el economista Carlos Toranzo Roca, acucioso investigador de la cara pluricultural y multilingüe de la Bolivia actual. Me concentraré en el trabajo de Toranzo para comenzar el análisis de lo que llamo metáforas del fluir.

El sugerente trabajo intelectual de Carlos Toranzo Roca aborda la óptica desterritorializadora desde la cual se hizo particularmente visible lo cholo, es decir, la construcción social más importante de "varios siglos de amestización" (Lo plurimulti 87 ). En efecto, los textos escritos por Toranzo en las décadas pasadas fueron ensayos descriptivos de la realidad que, dirigidos a las élites locales, pretendían 
que ellas, afanadas en autodefinirse como "criollas", pudiesen entender que, en realidad, eran el producto del largo proceso de mestizaje construido por la historia boliviana. Aún más, Lo pluri-multi o el reino de la diversidad era:

[...] un alegato contra las homogeneidades. Si bien describía el proceso de mestización, no hablaba de un mestizo único, es decir, discrepaba del modelo culturalista homogeneizador de la Revolución de 1952 que entendía que la historia revolucionaria iba a construir un solo modelo de mestizaje, uno único, monocultural. En la medida en que se diferenciaba del MNR revolucionario, lo hacía también de los revolucionarios soviéticos que pretendieron construir otra homogeneidad, la proletaria, matando u obscureciendo todos los matices de la diversidad, u ocultando las heterogeneidades que se iban cultivando cada día y que lo siguen haciendo en cualquier parte del mundo. (52)

Resulta sugerente comprobar que, un siglo después de publicado el ensayo de Tamayo, la realidad boliviana todavía plantea la necesidad de que se siga pensando el mestizaje. Nótese, sin embargo, que hacerlo ahora exige una óptica desterritorializadora muy diferente. En efecto, y al proseguir con lo que afirmaba en Lo pluri-multi, Toranzo vuelve, a raíz de la conmemoración de los veinticinco años de fundación del Posgrado en Ciencias del Desarrollo en la Universidad Mayor de San Andrés (Cides-UMSA), a escribir uno de los más interesantes ensayos de $\dot{i}$ Nación o naciones en Bolivia?, libro coordinado por el cientista social Gonzalo Rojas Ortuste. Se trata de "Repensando el mestizaje en Bolivia".

Repensar el mestizaje significa tener en cuenta que las diferencias raciales, supuestamente superadas por la modernización y la racionalización del Estado, no son un tema pasado, sino que, por el contrario, vuelven a ocupar el interés de los intelectuales del presente. En el fondo, se puede decir que, bajo el rótulo de la nación mestiza, la visión homogeneizadora de la realidad que, aparentemente, curó a Bolivia de la "enfermedad" racial que la aquejaba, reaparece con inusitada fuerza. La necesidad de repensar el mestizaje muestra que la nación mestiza, tal cual ella había sido pensada por las políticas pedagógicas del siglo pasado, necesitaba ser reinterpretada por nuevas demandas de índole varia: étnica, de género, generacional, regional, gremial, etc. De este modo, se percibía, a fines del siglo pasado, la necesidad de estudiar la conformación de los multiples mestizajes (Toranzo, "Repensando" 45). En efecto, afirmaba Toranzo, en la última década del siglo pasado, que "cerrar los ojos a las centenas de mestizajes de este país implica simplemente cerrar los ojos a las mayorías de Bolivia" (46).

Pero el estudio sobre los múltiples mestizajes, o la descripción de su largo proceso en Bolivia, tal cual aparece en el reciente ensayo de Toranzo, significan 
tener muy en cuenta que la construcción histórica "no es lineal sino iterativa, con momentos a veces llenos de violencia" (46) que llenan dicho proceso de "tonalidades", que no pueden ser abordadas como regularidades homogéneas, sino como heterogeneidades que deben ser reinterpretadas periódicamente. Sin embargo, note el lector que reinterpretar no significa refundar. En efecto, Toranzo afirma que "es falaz la idea de las refundaciones, como es equivocado el criterio que expresa que los fenómenos políticos se inician de cero, como si no [hubieran] [...] tenido ningún antecedente histórico" (46). En el fondo, Toranzo está planteando el fluir ordenado en el que se desplazan y mimetizan los mestizajes, identidades que "se construyen de la amalgama de pasado, de presente y de sueños de futuro" (46). Por ello, en el fluir de las identidades estarían las huellas de la historia que, buenas o malas, marcarían dichos procesos. Negarlos, como sucede, según Toranzo, con las políticas culturales del actual Estado plurinacional, propugnador de un indianismo que relega y subalterniza los mestizajes reales, conduciría a ver mal la realidad. Puesto que no existiría la identidad de lo boliviano como un hecho singular, Toranzo recurre a las identidades mestizas para replantear la necesidad de construir un nosotros común que sea capaz de reorientar el rumbo de la República de Bolivia, según él mal descrita por el Gobierno actual como Estado plurinacional.

Ahora bien, el desplazamiento de los mestizajes, su fluir en el tiempo, aleja a estos del territorio pedagógico, de la frontera dura delineada por Tamayo e impuesta más tarde por el "nacionalismo revolucionario", a principios de la década de 1950. Para Toranzo, este modelo nacionalista no habría perdido su relevancia, pero sí habría cambiado con el fluir del tiempo. Así, afirma Toranzo que los bolivianos, tanto rurales como urbanos, somos "datos de comunidad y presencia de diversidades" (49). Los bolivianos, sin embargo, habríamos mutado de modelo icónico -el fenómeno de las identidades es básicamente movimiento-, hecho que quiero destacar porque constituye uno de los acontecimientos más importantes de este ensayo, y que seguramente quedaría olvidado por otra lectura, de corte exclusivamente sociológico, que desatienda la representación. Me concentro, pues, en esta mutación, en esta metáfora del fluir que ahora representa las identidades desde una óptica muy diferente.

La lectura del ensayo de Toranzo me lleva a revisar uno de los libros del historiador argentino Ignacio Lewkowicz, dedicado al estudio de la subjetividad contemporánea (Pensar sin Estado). Lewkowicz acentúa el hecho de que hablamos frecuentemente del fluir de la conciencia, pero no reparamos en que estamos empleando una metáfora que se desplaza de un modo muy peculiar: corre como flumen, como un río que cambia y que nunca es el mismo. Pensado 
desde la orilla, nos dice Lewkowicz, "el río es la imagen de la fluidez concebida como 'cambio' que no se puede 'bajar dos veces" (235). Pero si en el río todo cambia, la mutación tiene un sentido ordenado, permanente: un nacimiento, un curso y una desembocadura. Así, "el río es el sentido del agua entre su fuente y su desembocadura" (235).

Esta imagen de la fluidez ordenada del río también permite repensar el mestizaje porque Toranzo recurre a ella para explicar, como ya observé, que "todo fluye en el tiempo", porque "nadie es idéntico a lo que era en el pasado" ("Repensando" 50). De este modo, Toranzo expresa, a través de esta metáfora heraclitana del tiempo, la apertura de la nación mestiza a procesos históricos mucho más complejos, que no dejan a nadie incólume, petrificado en su origen: "No, no hay calcos exactamente idénticos en la historia, eso es válido para toda la sociedad, incluidas sus élites, ellas han ido cambiando en el tiempo [... ${ }^{\prime \prime}$ (58). El resultado de todo proceso histórico es que nadie es idéntico a lo que fue en el pasado. No habría, pues, una nación mestiza inmutable, sino un proceso histórico, un fluir de las razas en permanente cambio. Nótese, sin embargo, que este fluir de los mestizajes tiene un final, una desembocadura precisa: la nación y la república.

El aspecto interesante, aunque también problemático, de esta fluida construcción multicultural de las identidades es precisamente la postulación del posible nosotros común que mediaría nuestros actos. Esta mediación tendría la capacidad de administrar los conflictos reales de manera tal que disiparía y resolvería, milagrosamente, hay que decirlo, la dificultad de construir la comunidad humana. Y estos conflictos se ahondan aún más cuando hay múltiples demandas de carácter étnico que los determinan y preceden.

A esta altura del análisis, cabe afirmar que el ordenado fluir de las identidades se desentiende del hecho de que la condición contemporánea se configura, como afirma Lewkowicz, "entre dos movimientos de distinta índole: por un lado, el desfondamiento del Estado; por otro, la construcción de una subjetividad que habita ese desfondamiento" (220). Y estas distintas formas de subjetividad que se construyen en el desfondamiento serían un nosotros muy diferente al que asume Toranzo como síntesis del curso seguido por la construcción de las identidades. Lewkowicz lo describe como un nosotros contingente (277). Contingit nosotros es "el pronombre de la alegría breve, nombre propio de la fiesta revoltosa y del Estado al borde de su disolución" (231).

¿Dónde se originaría este nosotros impreciso, extraño y precario, que, dado el descalabro de la institucionalidad del Estado, parece formarse, sin previo aviso, en esquinas y plazas, es decir, en asambleas que aparentemente dejan instalada una nueva manera de pensar? Este nosotros sería el resultado de una manera 
diferente de concebir la fluidez, porque, dado el desmoronamiento del Estado, respondería a la dispersión de lo contenido ante la falta de continente. Es el agua que, cual torrente incontrolable, fluiría sin desembocadura, "sin cartografía", sin dique que la contenga. Hablo, pues, de aguas turbulentas que, tal cual las tiene pensadas Toranzo, modificarían, alterarían el curso ordenado de las identidades. En efecto, la metáfora del río, afirmada como está en el fluir del proceso histórico, se desentiende de aquellos "atajos" que vienen del pasado y que crean turbulencia en las apacibles aguas de los mestizajes. Me parece que esta metáfora no representa esas avalanchas de agua y de tierra que bajan bateando debajo de la corriente cuando los ríos se cargan. En otras palabras, la metáfora del río se desentiende de aquellas "ruinas", de aquellos "torbellinos de pasado" que perturban nuestro presente porque responden a un más allá y a un entonces que de pronto se descubre; un pasado que no puede ser racionalizado y que es inservible para trazar el futuro. Ese allá y ese entonces que la metáfora del río encubre es el aquí que, siendo presente, se nutre de la memoria insomne pero fragmentada. Es el ahora que corre tanto como se ahonda verticalmente en un tiempo espeso que acumula sin sintetizar las experiencias a las que llamo rescoldos del pasado, producto de un tiempo circular, mítico, que se dejó atrás, pero que sigue perturbando con rabia y con violencia el presente. Hablo, pues, de anhelos postergados, hundidos en la memoria, que, al volver a la superficie, cobran nueva y repentina importancia social y política, originando así una conciencia contingente que, a diferencia de la proletaria, es el punto de partida del sacudón histórico que vivimos actualmente. Avalanchas, sacudones, turbulencias son, todos ellos, incorporaciones del pasado remoto que la metáfora del río, en su fluir ordenado y plácido, olvida registrar. A partir de dichas incorporaciones, aparecen los movimientos sociales que tienen hoy un rol específico en la dinámica del todo social. La avalancha y la turbulencia expresan el retorno de la multitud, de la plebe, a propósito de la cual me parece que sería conveniente seguir la huella dejada por "La forma multitud de la política de las necesidades vitales", tema y título del ensayo de Raquel Rodríguez, Álvaro García Linera y Luis Tapia, en el cual se describe detalladamente el alud de humanidad (162) que la multitud genera.

"La forma multitud de la política de las necesidades vitales", último ensayo del libro que, a propósito del retorno de lo plebeyo, escribieron sus tres autores, revela ampliamente los cambios producidos en la Bolivia de finales del siglo XX y principios del siglo XXI. En realidad, los acontecimientos de abril de 2000 marcaron el inicio del desmoronamiento del Estado-nación, la crisis del sistema neoliberal y la emergencia del nosotros contingente que, siguiendo el trabajo de Ignacio Lewkowicz, acabo de plantear. 
Los primeros meses del año 2000 hicieron que la ciudad de Cochabamba fuese el epicentro de una de las rebeliones sociales más importantes de la América Latina de nuestros días: la conocida guerra del agua. Entre enero y abril de ese año, se fue conformando en esta ciudad la Coordinadora del Agua y de la Vida, organización nueva, sin precedentes institucionales, que se opuso exitosamente a que el agua fuese privatizada, e impidió que, de acuerdo con una ley neoliberal promulgada a fines de 1999, el agua terminase siendo una mercancía y no un bien público.

$\mathrm{Al}$ reunir en asamblea a las asociaciones de regantes de los valles interandinos, a la Federación de Fabriles de Cochabamba, a los colegios de profesionales de clase media, a los sindicatos cocaleros y a los miembros de los ayllus de las zonas altas, esta Coordinadora del Agua fue, de acuerdo con los autores del ensayo, "una estructura organizativa con nuevas voces" (150) que emitieron el descontento de una "multitud plebeya" (150) que se representaba a sí misma en una enorme y espontánea asamblea callejera. Era la "densidad plebeya" (154) que, como un alud, como una avalancha, como un torrente humano, se "arremolinaba en calles, plazas y avenidas" (163), y que daba lugar a un "cabildo deliberativo" (154) sin precedentes. Esta multitud, que se "desbordaba por las calles para llegar al centro de la ciudad" (157), no era, pues, una estructura sindical tradicional, sino un grupo compuesto, mayoritariamente, por "bloqueadores agrarios, vecinos y vecinas humildes de la periferia de la ciudad" (139). La multitud que se levantaba en Cochabamba, en abril de 2000, para exigir el respeto a sus "usos y costumbres" (136), era una "presión centripeta" (143) que se inventó espontáneamente en ese dispositivo, extraño y precario para toda organización política tradicional, que es la asamblea constituida en esquinas y en plazas de la ciudad. Como lo expresa Lewkowicz, al referirse al nosotros contingente: " $[. .$.$] la asamblea primero necesi-$ tó reunirse en esquinas o en plazas para pensar de este modo. Y aunque luego se disolviera o extenuara como asamblea efectiva, dejó instalada esa modalidad de pensar. La asamblea es la mecánica efectiva del nosotros" (221).

La renovada modalidad de pensar también necesitó de una nueva metáfora que la expresase más apropiadamente. Me refiero, pues, a la avalancha, al alud, es decir, a la metáfora fluvial del aquí y del ahora sin cartografiar que es el presente. La avalancha es la acumulación violenta de asincronías, de tiempos encontrados, no contemporáneos, que rompen con la ordenada visión de la historia. Alejada de las playas, de la orillas seguras de la modernidad, del río que las representa y contiene; pensada desde un lugar de enunciación diferente y encontrado con la nación, la metáfora de la avalancha, de la turbulencia, desborda, como lo hicieron los guerreros del agua en los enfrentamientos sociales del año 200o. Según 
pudimos apreciar, el ensayo de referencia sobre la forma multitud reconstruye los días que siguieron al acontecimiento que dio inicio a la contemporaneidad boliviana: la guerra del agua.

Para los autores del ensayo, los guerreros del agua, quienes "bajaron a la ciudad encabezados por sus autoridades originarias" (168), no contemporizaron, sino "barrieron con la élite mestiza en el poder" (168). "Alud de humanidad que rebasó al Estado" (162), alzada de cholos y de campesinos, como también lo fue el acontecimiento revolucionario de 1952, que René Zavaleta Mercado relató con gran vigor en su Bolivia: el desarrollo de la conciencia nacional, los guerreros del agua fueron ese componente de "olores intensos de la muchedumbre que modifican el uso del espacio urbano en correspondencia a su sentido de fuerza y orgullo colectivo en movimiento" (Rodríguez, García y Tapia 154). Así, la densa avalancha de la plebe insurgente de Cochabamba fue la forma multitud que, expansiva como el agua (155), lo inundó todo, incluyendo los territorios despolitizados por el neoliberalismo. Esta multitud "atacó, debilitó y reformó los viejos espacios nacionales de la política" (155).

Es muy sugerente que los autores del ensayo sobre la forma multitud concluyan su trabajo sobre la Bolivia más reciente, sobre la Bolivia plebeya, refiriéndose a ella como la "marea alta de la política de las necesidades vitales" (177), metáfora que altera el ordenado fluir de las aguas del río, y muestra su caudaloso y desordenado desembocar en el mar. Si el río era el perpetuo fluir, el perpetuo devenir de las identidades mestizas, la "marea alta", el océano, parece ser el comienzo contingente de nuevos actores sociales que ya no fluyen ordenadamente, sino que, por el contrario, son el alud, la avalancha, la correntada, la marea y la resaca, el recomenzar perpetuo, el colapso del sentido del flumen y de las instituciones democráticas a las cuales representa.

Hecho significativo de este "alud de gente" producido en los albores del siglo XXI, y celebrado en el ensayo por su fuerza multitudinaria, fue el descubrimiento de la debilidad del Estado neoliberal mestizo, particularmente el descubrimiento de la pérdida progresiva de su capacidad "simbólica", de su función cohesionadora. Para sostenerse en el poder, el Estado debió recurrir a la violencia armada. El accionar del Estado neoliberal comenzó a perder validez y legitimidad ante los ojos de propios y ajenos, particularmente de aquellos que eran llamados a cumplir con los dictámenes arbitrarios que provenían del poder. De este modo, el "alud de humanidad que rebasaba las instituciones del Estado" (Rodríguez, García y Tapia 162) abría el nuevo ciclo, incierto, "sin cartografiar", de la "democracia de la plebe", cuya "marea alta" inundaba los espacios otrora despolitizados por el sistema imperante, y reabría una vez más 
los viejos esquemas nacionalistas que parecían haber desaparecido con la oleada neoliberal.

Llegado a este punto, no quiero terminar este apartado sin expresar que el ensayo de Rodríguez, García y Tapia sobre la forma multitud-su antecedente es "Forma clase y forma multitud en el proletariado boliviano", ensayo que Zavaleta escribiera a fines de 1970 en un tono menos celebratorio- concluye recordando a los lectores que si una de las funciones del "retorno de lo plebeyo" era la "rehabilitación de los usos y costumbres de los oprimidos" (177), otra de sus funciones también era la de traer al presente la vieja añoranza de Marx de que lo "arcaico" volviese a la modernidad en condiciones superiores, dándoles un renovado uso a las estructuras comunales agrarias. De este modo, el ensayo nos recuerda que "quedan en pie dos nuevas propuestas sociales de largo alcance: la autogestión político-económica y la comunidad o ayllu ampliado" (177). Ellas serían "los dos ejes discursivos de la multitud en acción" (177).

\section{La metáfora del anfibio}

Los recientes movimientos de las nacionalidades étnicas cuestionan, en mi criterio, lo que Rodríguez, Tapia y García Linera concibieron como "la marea alta de la política de las necesidades vitales" (77). En efecto, la resaca de la forma multitud me obliga a retornar a "tierra firme". Me refiero a la necesidad de recuperar el diálogo fecundo entre espacios y tiempos "contemporáneamente no contemporáneos", como el que promovieron los pueblos originarios de tierras bajas con la Marcha por el Territorio y por la Dignidad y la Búsqueda de la Loma Santa, acontecimientos que aunque tuvieron lugar en 1990 siguen alimentando el proceso de los movimientos indígenas más recientes. En ambas movilizaciones se dio una poderosa construcción de símbolos que, como señala la autora de un libro reciente sobre el tema (Canedo), forjó una nueva utopía, una resignificación territorial que propugnó la instauración de un nuevo orden social y económico. La utopía creada por estos pueblos originarios no desestimó la modernización; antes bien, la equilibró con símbolos ancestrales de identidad étnica que ayudaron al habitante de las tierras bajas, de la Amazonia, a resignificar su territorio. Este retorno a los ancestros, al pasado mítico, religioso, promovió una mayor tolerancia y comprensión de la compleja interacción entre los seres humanos y la naturaleza. Asimismo, generó nuevas asociaciones que cruzaron, desafiantes, aunque pacíficamente, los límites territoriales y pedagógicos trazados por el Estado, incluyendo las limitaciones de su percepción actual de qué debe entenderse por plurinacionalidad.

Ya observamos que si la "vertiente pedagógica" construía el Estado-nación, su desterritorialización producía, como efecto opuesto, el fluir identitario que 
remataba en su desfondamiento. Más allá de ambas, postulo aquí la (re)territorialización integradora, es decir, la posibilidad que tienen hoy los movimientos originarios de construir el diálogo, la fertilización recíproca entre la modernidad y la cultura ancestral. Me parece que lo anfibio es la metáfora que mejor expresa este nuevo desplazamiento. A ella recurrió Orlando Fals Borda cuando explicó el mundo riberano de Colombia, y hoy lo demanda el análisis de aquellos países y regiones donde la diversidad cultural es fuente de renovadas potencialidades interpretativas. Se trata, pues, de una metáfora útil porque "toma el conocimiento de un cierto contexto para llevarlo a otro, reelaborándolo en función del contexto de destino" (Mockus 37). Veamos la metáfora más detalladamente.

En sentido lato, anfibia, que significa ambas vidas o ambos medios, es toda comunidad que "se desenvuelve solventemente en varias tradiciones culturales y que facilita la comunicación entre ellas" (Mockus 37). Metáfora de la comunicación entre culturas, la del anfibio ayuda a superar las diferencias que se presentan en sociedades contemporáneas que tienen niveles elevados de diversidad cultural y de segmentación social. Por una parte, la metáfora acerca la ley a la moral y a la cultura, allí donde permanece el tradicional divorcio entre ellas. Por otra, el anfibio entrevé la posibilidad de superar la violencia a la que recurre el poder cuando resuelve conflictos. Si la metáfora del anfibio ilustra la posibilidad de elaborar normas compatibles con la diferencia, también muestra que es posible construir el diálogo entre las culturas.

Originalmente relacionada con una corriente de investigación que, liderada por Basil Bernstein, ve en la educación un proceso social de circulación del conocimiento, la metáfora del anfibio representa la capacidad que tiene la diferencia cultural para "obedecer a sistemas de reglas parcialmente divergentes sin perder integridad intelectual y moral" (Mockus 39). Es precisamente esta integridad la que ayuda al anfibio "a seleccionar y jerarquizar fragmentos de conocimiento y de moralidad en un contexto para traducirlo y hacer posible su apropiación en otro" (39). Lo aquí señalado se aplica a ese diálogo entre lo ancestral y lo moderno que me permite ubicar la Marcha por el Territorio y la Dignidad de los pueblos originarios de tierras bajas como un ejemplo revelador de la cultura de la integración que lo anfibio representa.

La Marcha por el Territorio y la Dignidad postuló una demanda social que cambió completamente el modo en que tenían lugar la dotación y la ocupación de tierras, ambas registradas como acontecimientos exclusivamente materiales en las historias agrarias de América Latina. En la marcha de los pueblos amazónicos no era solo la tierra, sino un conjunto imbricado de valores materiales y simbólicos lo que estos pueblos exigían que el Estado les reconociese. El 
territorio se transformaba, pues, en un símbolo de la reivindicación autonómica que los pueblos originarios exigían al Estado y a los grupos de poder que los habían sojuzgado. Como lo expresa Álvaro Bello, en el prólogo del reciente libro de Gabriela Canedo, La Loma Santa: una utopía cercada, a propósito de la resignificación del territorio:

Frente a la legalidad del Estado y de quienes buscan apropiarse de las tierras indígenas, el territorio es una evidencia material, demostrable y mensurable de los "derechos verdaderos" y originales porque es una "prueba" irrefutable de la pertenencia y del "lugar" de la identidad.

Este es el caso de los mojeños que, como señala Gabriela Canedo, buscan representar a través del territorio el lugar central para la existencia y reproducción material, el lugar donde se desarrolla la caza, pesca, recolección y cultivo para la subsistencia. Pero es también, señala la autora, el lugar de los símbolos de la identidad étnica. La Loma Santa, el territorio simbólico, es una utopía movilizadora que propugna la instalación de un nuevo orden social y económico. Y por ello es que su defensa es un motor de la acción colectiva de los mojeños, pues a través de esta lucha han podido posicionarse como un actor político $[\ldots](12)$

Al vivir tanto en la vida moderna como en la ancestral, los mojeños expresaban la capacidad que la diferencia cultural tenía para cruzar códigos culturales, para exigir que la legislación no relegase la costumbre sino que, por el contrario, la reconociese y la valorase. No era suficiente la legalidad impuesta desde el poder porque el mojeño, el habitante de las tierras bajas, intérprete y traductor de culturas, exigía, además, que la regla escrita no se desentendiese de la costumbre cultural. De este modo, las marchas de 1990 demandaban la fertilización recíproca de la ley con la moral y la costumbre. Y esta fertilización ayudaba, además, a la ampliación de la democracia porque permitía que lo legal se comunicase con lo moralmente válido y con lo culturalmente relevante, aunque el derecho positivo no los reconociese taxativamente. De este modo, el surgimiento de nuevas fronteras blandas, anfibias, capaces de conectar lo moderno con lo ancestral, permitía la (re)territorialización de conceptos que se entrelazaban para dar respuestas novedosas, creativas, a los avances depredadores del desarrollismo.

Frente al avasallamiento de las tierras de comunidad, frente a la colonización de los espacios rurales, la Marcha por el Territorio y por la Dignidad y la Búsqueda de la Loma Santa creaban, pues, la posibilidad de que los argumentos del pasado remoto "acortasen" la distancia entre las costumbres y la ley. En efecto, la fuerza de lo cultural buscaba reducir la separación entre las costumbres 
ancestrales y los procedimientos expresos que eran ajenos a las interpretaciones sagradas y a las motivaciones éticas que están fuera del alcance del derecho positivo. La funcionalidad sistémica de este, su razón instrumental, siempre sujeta a fines, eximía al derecho de tener que acudir a argumentos religiosos y culturales, y distinguía tajantemente los argumentos legales de los de aquellos grupos humanos que encontraban en la moral y en las costumbres ancestrales los valores que ampliaban sus libertades.

Finalmente, la puesta en práctica de argumentos culturales y religiosos que pertenecen al tiempo "de los dioses" (Chakrabarty) tiene enormes dificultades para influenciar el actuar comunicativo que se desarrolla en la "esfera pública". Ella desborda la razón instrumental del poder y del derecho positivo que lo legitima. Pero los pueblos anfibios que cruzan culturas, que las interrelacionan, parecen comprender que es urgente la compatibilidad de los sistemas y la adecuación de ellos a las necesidades del presente. Por ello, la fertilización recíproca de la ley, con la moral y la cultura, tiene hoy una sorprendente actualidad, habiendo ella confirmado que se lucha por la tierra y el territorio no solo para proteger los derechos humanos de los pueblos indígenas amazónicos, sino para extenderla a la protección de la naturaleza, de modo que su reconocimiento se torna en el "principal problema político y epistemológico del siglo XXI" (Komadina). En efecto, este problema epistemológico aparece con notable claridad en las recientes marchas de los pueblos indígenas de las tierras bajas, particularmente en la marcha por la defensa de los Territorios Indígenas del Parque Nacional Isiboro Sécure (Tipnis), que sigue teniendo lugar por el reclamo de legítimos derechos. Es el reclamo que los pueblos orginarios le hacen hoy al Estado, para exigirle el respeto no solo de los derechos que les garantizan sus derechos humanos, sino de aquellos que relacionan la naturaleza con la defensa del territorio. Bien sabemos hoy que de la observancia de estos derechos se desprende la mismísima razón de ser de la plurinacionalidad.

\section{Obras citadas}

Anderson, Benedict. Imagined Communities. Londres: Verso, 1983.

Arguedas, Alcides. Pueblo enfermo. 3. ${ }^{\mathrm{a}}$ ed. 1909. Santiago

de Chile: Ediciones Ercilla, 1937.

Bello, Álvaro. "Prólogo". La Loma Santa: una utopía cercada, por Gabriela Canedo. La Paz: Ibis; Plural, 2011. 2-12.

Bernstein, Basil. The Structuring of Pedagogic Discourse. Londres: Routledge, 1990.

Brown, Richard Harvey. A Poetic for Sociology. Toward a Logic of Discovery

for the Human Sciences. Chicago: University of Chicago Press, 1989. 
Calhoun, Craig. Nations Matter. Culture, History, and the Cosmopolitan Dream. Londres: Routledge, 2007.

Canedo Vásquez, Gabriela. La Loma Santa: una utopía cercada. La Paz: Ibis; Plural, 2011.

Chakrabarty, Dipesh. Provincializing Europe. Postcolonial Thought and Historical Difference. Princeton, NJ: Princeton University Press, 2000.

Duara, Prasenjit. "Historicizing National Identity, or Who Imagines What and When". Rescuing History from the Nation: Questioning Narratives of Modern China. Eds. Geoff Eley y Ronald Grigor Suny. Chicago: University of Chicago Press, 1995• 45-56.

Fals Borda, Orlando. "Investigating the Reality in Order to Transform It: The Colombian Experience". Dialectical Anthropology 4 (1979): 33-55.

Komadina, Jorge. 2011 "Derechos del Tipnis". Web. 28 de noviembre de 2011. $<$ http://www.la-razon.com/version.php?Articleld $=137505 \&$ Editionld $=2653>$.

Larson, Brooke. "Indios redimidos, cholos barbarizados: imaginando la modernidad neocolonial boliviana (1900-1910)". Visiones de fin de siglo. Bolivia y América en el siglo XX. Comps. Dora Cajías, Magdalena Cajías, Carmen Johnson e Iris Villegas. La Paz: Instituto Francés de Estudios Andinos (IFEA); Coordinadora de Historia; Embajada de España en Bolivia, 1998.

Lewkowicz, Ignacio. Pensar sin Estado. La subjetividad en la era de la fluidez. Buenos Aires: Paidós, 2004.

Mayorga, Fernando y Ramiro Molina Barrios. La Asamblea Constituyente y las representaciones sociales de nación/naciones. La Paz: Unidad de Coordinación de la Asamblea Constituyente, 2005.

Mockus, Antanas. "Anfibios culturales y divorcio entre ley, moral y cultura". Análisis Político 21 (1994): 37-48.

Montenegro, Carlos. Nacionalismo y coloniaje. La Paz: Juventud, 1943.

Pérez Vejo, Tomás. "La construcción de las naciones como problema historiográfico: el caso del mundo hispánico". Historia Mexicana 2. México: El Colegio de México, 2003. 275-311.

Rodríguez, Raquel, Álvaro García Linera y Luis Tapia. "La forma multitud de la política de las necesidades vitales". El retorno de la Bolivia plebeya. La Paz: Muela del Diablo Editores, 2000. 34-49.

Said, Edward. Representations of the Intellectual. Nueva York: Vintage Books, 1996. Sanjinés, Javier. El espejismo del mestizaje. La Paz: Instituto Francés de Estudios Andinos (IFEA); Programa de Investigación Estratégica en Bolivia (PIEB); Embajada de Francia en Bolivia, 2005.

- Rescoldos del pasado. Conflictos culturales en sociedades postcoloniales. La Paz: Programa de Investigación Estratégica en Bolivia (PIEB), 2009. 
Smith, Anthony. The Ethnic Origins of Nations. Oxford: Blackwell, 1981.

- The Ethnic Revival in the Modern World. Cambridge:

Cambridge University Press, 1986.

Soruco Sologuren, Ximena. La ciudad de los cholos. Mestizaje y colonialidad en Bolivia, siglos XIX y XX. Lima: Instituto Francés de Estudios Andinos (IFEA); Programa de Investigación Estratégica en Bolivia (PIEB), 2011.

Tamayo, Franz. Creación de la pedagogía nacional. 3. ${ }^{\mathrm{a}}$ ed. 1910. La Paz: Biblioteca del Sesquicentenario de la República, 1975.

Toranzo Roca, Carlos. Lo pluri-multi o el reino de la diversidad. La Paz: Instituto Latinoamericano de Investigaciones Sociales (Ildis), 1993.

— "Repensando el mestizaje en Bolivia". ¿Nación o naciones boliviana(s)? Ed. Gonzalo Rojas. La Paz: Posgrado en Ciencias del Desarrollo en la Universidad Mayor de San Andrés (Cides-UMSA); Embajada de España en Bolivia; Universidad Complutense de Madrid, 2009 • 45-61.

Vidal, Hernán. La literatura en la historia de las emancipaciones latinoamericanas. Santiago de Chile: Mosquito Comunicaciones, 2004.

- "An Aesthetic Approach to Issues of Human Rights". Hispanic Issues On Line (número dedicado a Human Rights and Latin American Cultural Studies, eds. Ana Forcinito y Fernando Ordóñez) 4.1 (2009): 14-43.

Zavaleta Mercado, René. "Forma clase y forma multitud en el proletariado boliviano". Bolivia hoy. México: Siglo XXI Editores, 1987. 89-97.

- Bolivia: el desarrollo de la conciencia nacional. La Paz:

Editorial Los Amigos del Libro, 1967. 